\title{
ACERCA DE LOS INICIOS DE LA DIVULGACIÓN DEL PSICOANÁlisis EN ARgENTINA: UN ANÁLISIS DE ESCUELA PARA PADRES*
}

\section{Karina Savio**}

\section{Resumen}

En este artículo nos proponemos analizar los tres tomos de Escuela para Padres de Eva Giberti. Buscamos, por un lado, reflexionar sobre el dispositivo enunciativo que allí surge (Maingueneau, 1987, 1999; Amossy, 2005) y, por el otro, rastrear el modo o los modos en que se construye, formula y reformula el saber experto en estos textos (Authier, 1993, 1995). El trabajo ha revelado que la divulgadora/enunciadora no se presenta como una simple mediadora entre el público lector y el saber del experto, sino que, por el contrario, las imágenes que se construyen en torno a su figura y al vínculo con el enunciatario presentan distintos matices y generan diversos efectos de sentido en el entramado discursivo. Por otra parte, se ha advertido que el nuevo saber al que se refieren no se manifiesta como inalcanzable o cerrado a la comunidad psicoanalítica.

Palabras clave: análisis del discurso, divulgación, psicoanálisis.

\section{ABOUT THE BEGINNING OF THE POPULARIZATION OG PSYCHOANALYSIS IN ARgENTINA: AN ANALYSIS OF SCHOOL}

\section{FOR PARENTS}

\begin{abstract}
In this article, we analyze the three volumes titled Escuela para Padres, written by Eva Giberti. We seek, on the one hand, reflect on the enunciative device (Maingueneau, 1987, 1999; Amossy, 2005) and, on the other, consider the mode or the modes in which it is constructed, formulate and reformulate the expert knowledge in these texts (Authier, 1993, 1995). This study has identified that in these texts the enunciator is not presented as a simple mediator between the public readers and the expert knowledge, but, on the contrary, the images that are constructed around its figure and the relation with the addresses have different nuances and generate various sense effects in the discursive framework. On the other hand, it has concluded that the new knowledge they refer to does not appear as out of reach, closed to the psychoanalytic community.
\end{abstract}

Keywords: discourse analysis, popularization, psychoanalysis.

* Este artículo forma parte de la investigación "Saber, tradición, discurso: un estudio sobre los modos de transmisión del psicoanálisis del niño en la Argentina (1957-1961)" desarrollada en el marco de CONICET.

** Argentina. Doctora en Letras. Universidad de Buenos Aires, Universidad Nacional Arturo Jauretche (Pcia de Buenos Aires), CONICET. karinasavio@fibertel.com.ar 


\section{Introducción}

La teoría sobre el inconsciente de Sigmund Freud ingresa tempranamente en los circuitos académico-científicos, culturales y periodísticos de la Argentina, promoviendo la incorporación de un conjunto de términos psicoanalíticos -proyección, represión, libido, identificación, Edipo, negación, inconsciente, entre otros- al habla cotidiana de los argentinos. Estas huellas en el lenguaje evidencian así el lugar significativo que el discurso psicoanalítico ocupa en el imaginario social y manifiestan el alcance de la progresiva y gradual popularización del pensamiento del médico vienés en esta sociedad.

A principios del siglo pasado, el psicoanálisis se instala a través de los callejones de la psiquiatría como un saber polémico, objeto de elogios y críticas, y, en los años `20 y `30, se expande y prolifera hacia otros espacios no médicos como "una de las corrientes espirituales más importantes del momento" (Plotkin, 2003, p. 41). Así es como comienzan a emerger ciertas voces que intentan acercar estas nuevas ideas a un público más amplio: en la década del '20, por ejemplo, la revista El Hogar publica diversos artículos sobre el psicoanálisis; en 1931, en el diario Jornada se incorpora una columna sobre la interpretación de los sueños en la que se analizan los sueños de los lectores; la Editorial Tor, a su vez, pone a la venta, en 1933, una traducción de la biografía de Freud escrita por Stefan Zweig y, en 1935, una serie titulada Freud al alcance de todos, escrita por el poeta peruano Alberto Hidalgo ${ }^{1}$. Sin embargo, habrá que esperar algunos años más para que esta teoría se instale con mayor vigor en el entretejido social de este país. Será a mediados de la década del '50 y a lo largo de los '60 que se produce lo que Balán (1991) denomina el boom del psicoanálisis.

1957 es un año instituyente para la historia de la psicología argentina: en ese año se crea la carrera de Psicología de la Universidad de Buenos Aires y el Instituto Nacional de Salud Mental ${ }^{2}$. En ese mismo año, Arminda Aberastury organiza el Primer Simposio de Psicoanálisis de Niños en la Asociación Psicoanalítica Argentina (APA), que será publicado por la Revista de Psicoanálisis un año después. En ese contexto nace la primera

1 Para una ampliación sobre la llegada de la teoría freudiana a Buenos Aires, véase Balán (1991), Plotkin (2003), Vezzetti (1996).

2 Para un estudio sobre la historia del psicoanálisis en su relación con la Salud Mental en Argentina, véase Carpintero y Vainer (2004). 
Escuela para Padres bajo la iniciativa de Eva Giberti, quien, a partir de 1957, comienza a publicar una columna destinada a la divulgación psicológica sobre la crianza infantil en La Razón y en diversas revistas: Nuestros Hijos, Claudia, Vosotras, Histonium, y Damas y Damitas ${ }^{3}$. La creciente popularidad que estas columnas logran conduce, en 1961, a la publicación de tres volúmenes titulados Escuela para Padres, en los que Giberti recopila los segmentos escritos hasta aquel año. El éxito que obtienen estos artículos se reproducirá también en la venta de estos volúmenes, que llegarán a las treinta ediciones, con cinco mil ejemplares cada una.

En este artículo nos proponemos analizar los tres tomos de Escuela para Padres escritos por Eva Giberti, debido al carácter cuasi fundacional ${ }^{4}$ que estos artículos presentan en la historia sobre la divulgación del psicoanálisis en Argentina. Buscamos, por un lado, reflexionar sobre el dispositivo enunciativo que allí surge, y, por el otro, rastrear el modo o los modos en que se construye, formula y reformula el saber experto en estos textos. Consideramos, en este sentido, que un estudio sobre el discurso de la divulgación del psicoanálisis contribuye a pensar, entre otros aspectos, no solamente sobre su tradición discursiva (Kabatek, 2006) en la Argentina, sino también sobre las distintas formas que fue adquiriendo esta teoría en su circulación por el entramado social.

La relevancia que encuentran estos escritos de Eva Giberti en el devenir del movimiento psicoanalítico, como plantean Carpintero y Vainer (2004, p. 128), no ha sido siempre reconocida: suelen ocupar un lugar marginal e, incluso, muchas veces han sido olvidados dentro de la historia "oficial". Esto se debe, según estos escritores, a la formación profesional de la autora. En ese entonces, Giberti todavía no está recibida de psicóloga y su título era el de asistente social. A esta justificación le podríamos añadir otros dos motivos por los que posiblemente esta publicación haya quedado desterrada de la memoria histórica. En primer lugar, mientras que el psicoanálisis "oficial" de la APA, en esos años, es profundamente kleiniano, Giberti recurre a Ana Freud y a otros discípulos de Freud -en particular, al denominado nuevo psicoanálisis-

3 Escuela para Padres se clausura en 1972. Según señala la misma autora (1996), en 1973 fue excluida de todos los medios de comunicación debido a la detención de su hijo por razones políticas.

4 Matizamos aquí el carácter fundacional de los textos de Giberti dado que, como hemos advertido, el psicoanálisis aparece tempranamente en los medios de comunicación. No obstante, hasta ese entonces, no había alcanzado una repercusión tan masiva. 
que se distancian de la corriente inaugurada por Melanie Klein. Esta posición teórica nos permite sospechar la existencia de cierta grieta con los psicoanalistas de aquella época. En segundo lugar, no todas las notas de Escuela para Padres abordan o remiten a temas psicoanalíticos de manera específica.

Por último, queremos destacar que los trabajos de Eva Giberti no han sido, hasta la fecha, analizados desde una perspectiva discursiva. Las únicas referencias a estos textos corresponden a las que ha realizado la propia autora y a las que se desprenden de algunos estudios históricos. Por un lado, Giberti $(1990,1996)$ los ha cuestionado en reiteradas ocasiones no solo por el contenido de lo que allí se desarrolla, sino también por la forma en que se transmite el mensaje. Por el otro, en su relación con la historia, Plotkin (2003) -quien hace una breve mención al estilo singular de escritura de Giberti- y Carpintero y Vainer (2004) los han recuperado en sus relatos sobre el psicoanálisis en la Argentina. Borinsky (2005), por otra parte, los incluye como objeto de estudio en su historia sobre la divulgación de las prácticas de crianza.

El artículo desarrolla, en un primer momento, los aspectos teóricometodológicos dentro de los que se encuadra el trabajo realizado y, en un segundo momento, la estructura de las notas que forman parte de los tres volúmenes. Finalmente, se detiene en el análisis del dispositivo enunciativo y del modo o de los modos en los que se construye el saber a lo largo de estos textos.

\section{Aspectos teórico-metodológicos}

Este trabajo se inscribe dentro de los estudios sobre el discurso de la divulgación. Antes de exponer algunos puntos nodales para nuestra investigación, quisiéramos realizar dos aclaraciones sobre esta nominación. En primer lugar, entendemos aquí el discurso como un concepto teórico y metodológico, y no como una unidad de análisis. En tal sentido, es un objeto a construir que, por tanto, no tiene límites precisos. En segundo término, consideramos que esta categoría, discurso de la divulgación, que reenvía a una actividad -la de divulgar- y que se presenta con cierto viso homogéneo, es una abstracción cuya denominación cristaliza su carácter dinámico. En efecto, la naturaleza cambiante de los discursos implica concebir un movimiento en permanente tensión: de allí que sostengamos que no existe $e l$ discurso 
de la divulgación, pensado como un discurso preexistente, localizado y localizable. Sin embargo, esto no impide ubicar, al decir de Orlandi (1987), ciertas constantes que articulan lo lingüístico y lo social, y que pueden rastrearse en los diferentes discursos 5 .

En función del análisis que realizamos en los apartados siguientes, nos interesa puntear dos problemáticas que se han estudiado en torno a la divulgación científica: el lugar de la reformulación y su vinculación con el problema de la comunicación, y, relacionado con esto, el esquema trilogal. Numerosos investigadores (entre ellos, Authier, 1982; Beacco y Moirand, 1995; Calsamiglia y Van Dijk, 2004; Ciapuscio, 2007; Fuchs, 1994; Mortureux, 1982) han advertido que la práctica de reformulación es esencial y constitutiva de esta actividad. Al divulgar, se entrecruzan dos mundos: por un lado, el de los científicos y, por el otro, el del público general. Authier (1982), en este sentido, compara el lenguaje científico con una lengua extranjera, por lo que manifiesta que en la divulgación se ponen en contacto dos lenguas: la del científico y la del lector no especializado. En este cruce, para que el diálogo pueda establecerse, es necesario, entonces, que se recurra a la reformulación. El texto que se produce (T2) parte de uno anterior (T1), nacido al interior de la comunidad científica, que no puede ser transmitido si no es, primero, adaptado y revisado en función de los nuevos interlocutores. Por ello, Fuchs (1994: 8) se refiere a que en la divulgación se recurre a la reformulación explicativa. En este tipo de reformulación, a diferencia de la reformulación imitativa, se plantea una distancia con la situación de producción original y el texto reformulado (T2) reenvía al texto original (T1) y a su enunciación con el objetivo de hacerlo más inteligible. Calsamiglia y Van Dijk (2004) señalan, incluso, que la divulgación no solamente presupone una reformulación, sino también una recontextualización, en la que se consideran las propiedades del nuevo contexto comunicativo. Este aspecto discursivo, asociado a la comunicación, ha promovido diversas investigaciones que se han centrado en el nivel metalingüístico (Mortureux, 1982), en las calificaciones metadiscursivas (Ciapuscio, 2007) y en el uso de estrategias explicativas -definiciones, metáforas, descripciones, ejemplos, entre otros- (Calsamiglia y Van Dijk, 2004; Ciapuscio, 2005; Knudsen, 2002; 
Williams Camus, 2009) en diferentes géneros destinados a la divulgación de las ciencias.

Por otra parte, diversos estudios (Authier, 1982; Calsamiglia, 1997; Moirand, 2006) han destacado que la divulgación científica supone un esquema trilogal, que comprende los tres participantes involucrados en el acto: el divulgador, el científico o la ciencia, y el lector. Este esquema no implica la interlocución directa entre estos tres participantes, ya que, en verdad, es el divulgador quien se presenta como aquel capaz de mediar entre la ciencia y el lector. Por tal razón, es quien tiene a su cargo la tarea de reformular y transformar el saber científico en un saber accesible a todos. La relación, entonces, que el divulgador establece en el texto con la ciencia y también con el lector es primordial en este tipo de discurso, por lo que debe posicionarse como un mediador autorizado para articular estos dos polos, que se constituyen en lugares de enunciación. En algunos momentos, el divulgador se acerca más a la voz del científico y, en otros, más a la voz del lector. La importancia del vínculo que se establece entre el divulgador y el público al que se dirige ha sido objeto de análisis en diversos trabajos (Hyland, 2009, 2010), en los que se ha puesto el foco, entre otras cuestiones, en los modos en los que se construye la proximidad con el lector.

Estas problemáticas que hemos mencionado -la reformulación y el esquema trilogal-no deben interpretarse desde una concepción lineal de la divulgación. Consideramos, siguiendo a Moirand $(2003,2006)$, que esta concepción simplifica la complejidad en la comunicación. De acuerdo con esta autora, el discurso de la divulgación es un discurso heterogéneo, conformado por discursos provenientes de diferentes comunidades. De esta forma, según ella, no habría un único discurso primario y el divulgador no sería un mero intermediario entre este discurso y un lector pasivo en su recepción. De allí que prefiera el término "circular" cuando se refiere al modelo de la divulgación. Beacco, Claudel, Doury, Petit, Reboul-Touré (2002) ya plantean esta línea al analizar los nuevos actores que intervienen en la transmisión de la ciencia en la actualidad: el lugar del periodista-mediador ha sido desplazado, para ellos, por el del periodista que produce su discurso en base a un conjunto de discursos que no se originan únicamente en la ciencia; por su parte, el público ha dejado de ser un receptor inactivo y su voz se manifiesta de diversas maneras. Por estos motivos, estos autores plantean la presencia de un 
modelo "plurilogal". Pensamos que esta heterogeneidad, que está en consonancia con lo que señalamos al comienzo de este apartado sobre el término discurso, debe ser contemplada al momento del trabajo analítico.

En este texto, siguiendo esta perspectiva teórica, analizamos los tres tomos de Escuela para padres escritos por Eva Giberti publicados por primera vez en 1961 por Esece Editora ${ }^{6}$. Trabajamos aquí con la $11^{\text {a }}$ edición de $1968^{7}$. Tomando en cuenta la corriente francesa de análisis del discurso, nos interesa reflexionar, en primer lugar, en torno al dispositivo enunciativo (Maingueneau, 1987, 1999; Amossy, 2005) que se construye discursivamente en los artículos agrupados en estos volúmenes. Nos interrogamos, así, acerca de los modos en que la divulgadora/ enunciadora y el enunciatario al que ésta se dirige están configurados en estas notas y también acerca del vínculo que se establece entre ambos. En segundo lugar, en relación con las modalidades en que se despliega el saber, estudiamos, por un lado, la incorporación de la palabra ajena autorizada. Precisamos allí el tipo de cita que se emplea -cita textual, cita mención, cita reformulación, cita mixta-, las particularidades que estas citas adoptan y la procedencia disciplinar de las voces a las que se recurre. Por el otro, rastreamos los lugares en los que se emplean conceptos y / o términos psicoanalíticos e identificamos tanto la presencia o no de comentarios metaenunciativos (Authier, 1993, 1995) como el efecto discursivo que el lenguaje psicoanalítico genera en el entramado textual.

\section{Una estructura en tres tiempos}

Las notas que se reúnen en los tres volúmenes de Escuela para padres no siguen una estructura textual homogénea: esta depende, en efecto, del tema a tratar. Algunos artículos, por ejemplo, relatan el viaje de la autora por algunos establecimientos europeos y narran sus impresiones

6 Para este trabajo, no tomamos en consideración las publicaciones donde aparecieron las notas por primera vez por dos razones. En primer lugar, la propia autora afirma en la introducción que estos artículos fueron modificados en función del nuevo contexto comunicativo, lo que permite analizar este material con cierta presunción de autonomía. En segundo lugar, estas fuentes son heterogéneas en su constitución: el diario La Razón se distingue discursivamente de las revistas y estas, a su vez, difieren entre sí.

7 Estos volúmenes fueron publicados en tomos de tapa dura, con el título del libro en letras doradas y, sobre él, imágenes de niños sonrientes. En su interior, también figuran diversas ilustraciones que son inspiradas a partir de distintas frases que surgen de las notas. La $11^{a}$ edición no se diferencia de las anteriores, salvo por un pequeño apartado que la autora incluyó en la $8^{a}$ edición. 
profesionales, por lo que su organización se distingue de la de otros en los que se aborda alguna problemática infantil en particular. No obstante, a pesar de estas diferencias, podemos encontrar una estructura prototípica a la que la mayoría de estos textos se adapta, conformada por tres tiempos discursivos:

1. Recuperación de creencias y/o prácticas populares a través de su puesta en escena.

2. Confrontación entre esas creencias y/o prácticas, y el saber experto.

3. Síntesis final a partir de la enunciación de un principio.

Para desarrollar este esquema, nos valdremos de un ejemplo. La nota titulada "Desconfianza en los hijos" (Giberti, 1968, t.I, p. 46) nos servirá de guía. Esta nota comienza de la siguiente manera:

1. Cuando papá llegó aquella noche se sorprendió al ver que mamá no estaba todavía lista para salir:

-¡Cómo! ¿No te cambiaste todavía?... Mirá que el cine empieza a las ocho y tenemos que viajar... (Giberti, t.I, p. 46)

A partir de estas líneas, en tono narrativo, se despliega una breve escena cotidiana en la que la madre le confiesa a su marido que no pudo bañarse porque, frente al temor a que le ocurriese algo a su hija, no la quiso dejar sola. Este primer tiempo reenvía a la voz del lector, en tanto exhibe una posible escena de su vida cotidiana. De esta forma, no solo pone de relieve el tema a tratar o lo introduce, sino que también escenifica los miedos, las ideas y las prácticas, promoviendo la identificación: la madre/lectora se reconocerá, pues, en aquella mujer que "desconfía" de sus hijos. Es interesante mencionar que en este primer tiempo encontramos ecos de la presentación de casos clínicos en psicoanálisis ${ }^{8} \mathrm{y}$ la relevancia que la narración esgrime en su puesta en palabras.

8 No podemos dejar de evocar que la escritura asociada a la práctica clínica aparece dentro de la literatura psicoanalítica en su mismo gesto fundador. Nos estamos refiriendo aquí al caso de Bertha Pappenheim, más conocida como Anna O., quien fuera la primera analizante dentro del movimiento psicoanalítico. La importancia de su tratamiento no debe atribuirse únicamente a que constituye el punto de partida de la talking cure, de la cura por medio de la palabra. Publicado en Estudios sobre la histeria (Freud, 1980), la escritura de este caso inaugura una práctica discursiva cuya vigencia perdura en la actualidad. Desde este momento inicial, la clínica no abandonará las páginas de los escritos psicoanalíticos, erigiéndose como uno de sus pilares esenciales. 
La voz de la divulgadora/enunciadora recién aparece cuando finaliza el relato. En este segundo momento, apelando al saber experto, desnuda el error de la trama:

2. Esta escena es mínima reproducción de una línea de comportamiento familiar poco aconsejable para llegar a formar seres independientes y normales. (...)

No carece de valor indagar por qué actúa así papá o mamá. Es certera la opinión de G. Durandin en este sentido: “... el bien y el mal se presentan todavía para muchos de nosotros como tabúes, y el mal, como un peligro permanente. (...)" (Giberti, 1968, t.I: 47-48)

En este segundo tiempo las creencias y prácticas populares se contraponen al saber experto. Por tal razón, se devela que aquel accionar de la madre es inadecuado y se fundamenta esta posición, en este caso, a partir de la palabra autorizada de Durandin. Es aquí donde el saber experto emerge para rectificar el comportamiento de esta mujer, por lo que la divulgadora/enunciadora utiliza diferentes estrategias para alcanzar tal propósito: definiciones, ejemplos, descripciones, paráfrasis, comparaciones, entre otras. ${ }^{9}$

En el tercer tiempo, como conclusión, se formula un principio que se ajusta al caso en cuestión y que sintetiza lo expuesto previamente: "Los chicos, los adolescentes, necesitan del aval, la sugerencia y el sostén emanados de la presencia adulta, pero también de su confianza" (Giberti, 1968, t.I, p. 48). Este último tiempo cierra el artículo y suele presentar un mensaje breve, claro y conciso, que no da lugar a equívocos.

\section{El dispositivo enunciativo}

Ahora bien, ¿cómo se presenta el dispositivo enunciativo en estos artículos?, ¿cómo se manifiesta la voz de la divulgadora/enunciadora?, ¿cuál es el lugar del otro, del lector, en estos textos? El análisis de este dispositivo ha puesto en evidencia dos características que atraviesan los volúmenes: la proximidad entre la voz de la divulgadora/enunciadora y

9 Como no es un objetivo de esta presentación, no estudiaremos las estrategias explicativas que surgen de las notas. 
la voz del lector, en primer lugar, y el lugar que el Otro materno ocupa en la construcción discursiva, en segundo lugar. Siguiendo lo que señalamos en el segundo apartado, estos rasgos permiten interrogar la concepción del divulgador como un mero mediador entre el público y el saber.

\subsection{La proximidad de voces}

Ya hemos afirmado que la voz del divulgador -que pone en relación el saber, por un lado, y el público general, por el otro- puede generar un efecto de cercanía hacia uno de estos dos lugares. En nuestro corpus, en sintonía con el propósito explicativo de la publicación ${ }^{10}$, detectamos una marcada preocupación por acortar la distancia entre la divulgadora/enunciadora y el público al que ella se dirige a través de dos rasgos: la acentuación de la comunidad con el lector y el empleo de un tono conversacional. Mientras que Hyland (2010) sostiene que en la divulgación la credibilidad se establece a partir de las fuentes citadas, en los materiales analizados la credibilidad aparece promovida a través del tipo de vínculo que se establece entre ambos polos de la enunciación: la divulgadora/enunciadora y el enunciatario.

\subsubsection{La comunidad con el lector}

$\mathrm{Al}$ comienzo de nuestro trabajo hemos comentado que la autora de estas notas, Eva Giberti, no estaba recibida de psicóloga al momento de la publicación de los volúmenes, pero sí había obtenido el título de asistente social. Incluso, en aquel entonces, trabajaba en un hospital de niños. No obstante, en estos artículos no se hace referencia a su práctica hospitalaria ni a su formación universitaria. Por el contrario, la voz que toma a cargo la enunciación se presenta alejada de la imagen del experto, despojada del viso profesional y, en consecuencia, más cercana a la figura del lector. ${ }^{11}$

En primer lugar, en el primer tiempo discursivo, en el que se recuperan las creencias y/o las prácticas sociales, no se utiliza el trabajo

10 Ya hemos señalado en el apartado 2 la relación entre la divulgación y la explicación. Para este caso, es interesante resaltar que del mismo título de las notas "Escuela para padres" se desprende su fin didáctico, que apunta, en última instancia, a la modificación de las prácticas de crianza.

11 En otro trabajo hemos analizado que, a diferencia de esta publicación, en los fascículos de Escuela para padres, escritos por Giberti y publicados por Página 12 en 1999, la imagen de la divulgadoraenunciadora se corresponde con la imagen del experto (Savio, 2015). 
hospitalario como material de análisis. En efecto, la mayoría de las veces la divulgadora/enunciadora apela a experiencias cotidianas para armar sus relatos. Se ubica, entonces, en el lugar de "madre", "niña", "vecina":

3. El caso de mi vecinito no es infrecuente (Giberti, 1968, t.I, p. 246)

4. La verdad es que siempre guardaré una inolvidable gratitud hacia aquel médico que, siendo yo chiquita, recetó solemnemente: “Supresión de la sopa..." (Giberti, 1968, t.II, p. 187)

5. Este caso, que conozco muy de cerca, ya que el chico "protegido" era mi hijo, demuestra hasta dónde es falso el concepto de la influencia perniciosa por parte de los compañeros de juego. (Giberti, 1968, t.III, p. 194)

En estos breves fragmentos, vemos que se emplean situaciones domésticas, familiares, para elaborar las escenas que inician las notas. Los ejemplos 4 y 5, incluso, figuran al finalizar los artículos, generando así un guiño lúdico con el interlocutor.

Esta escasa alusión al material clínico se explicita en el segundo tomo ${ }^{12}$ :

6. Más de una vez alguien me ha preguntado de dónde tomo los temas para mis escritos; a nadie se le escapa que muy pocas veces echo mano del fichero de casos de clínica de conducta. Es suficiente el hablar de los chicos corrientes, normales, que todos conocemos y de los adultos que se relacionan con ellos (Giberti, 1968, t.II, p. 133)

En esta aclaración, observamos que el rasgo que se valora es el de la "normalidad". Asimismo, se emplea un 'nosotros inclusivo' a través del cual el lector y la divulgadora/enunciadora quedan incorporados en un mismo colectivo.

En segundo lugar, en el segundo tiempo, al momento de confrontar estas experiencias con el saber experto, y en el tercer tiempo, al presentar 
la síntesis, la enunciación también recae en los roles de "madre" o de "hija":

7.nosotros también hemos sido hijos tal como hoy día lo son los nuestros. ¿Qué nos pasó a nosotros para que hoy tengamos tanto que corregir? (Giberti, 1968, t.I, p. 257)

8. claro que los que tenemos chicos sabemos que esto no lo asimilan antes de provocar cuatro o cinco catástrofes (Giberti, 1968, t.II, p. 11)

Como en el ejemplo 6, en estos fragmentos se recurre al 'nosotros inclusivo'. Mediante este uso del nosotros, la divulgadora/enunciadora se nombra, junto con el lector, dentro del colectivo "madres" y del colectivo "hijos".

Este lugar de enunciación -Eva como "madre", "hija", "vecina" - la acerca al otro, facilita que el otro se identifique con los relatos, con los casos que allí se narran. De esta forma, la divulgadora/enunciadora se presenta como una mujer corriente, una mujer común; podría confundirse, en verdad, con uno de los tantos lectores de sus propios escritos. Por ello, expresa sus emociones y puede "comprender", gesto que, a su vez, promueve la empatía:

9. Por ello me conmovió encontrar la cita de este trabajo en una institución que, entre nosotros, demuestra estar al tanto del problema (Giberti, 1968, t.I: 74)

10. Claro está -y yo lo comprendo muy bien-que los chicos son difíciles de soportar (Giberti, 1968, t.I: 153)

En estas citas nos encontramos que la divulgadora/enunciadora se muestra como un sujeto que comparte sentimientos con el público lector.

Por último, quisiéramos señalar que en el único colectivo "profesional" en el que la divulgadora/enunciadora se incluye es el de "maestras". En diversas notas, ella realiza una fuerte crítica a la educación tradicional y, por ello, recuerda su trabajo como docente. De esta manera, al haber formado parte del sistema escolar y conocer por su propia experiencia la situación educativa del país se habilita a ejercer este cuestionamiento ${ }^{13}$. 
Sin embargo, en los demás artículos, no apela a su lugar de pedagoga en la construcción de las escenas, ni relata casos de su trayectoria docente.

\subsubsection{El tono conversacional}

Otro rasgo que se evidencia luego de una recorrida por estos volúmenes es la aparición de un tono conversacional, que, como en el caso anterior, tiene como efecto acortar la distancia entre la divulgadora/ enunciadora y el público lector, lo que contribuye al fin didáctico. Este tono se palpa, en primer término, a partir del uso de un lenguaje llano, coloquial, en el que el lector puede reconocerse. La ausencia de tecnicismos, de un vocabulario especializado, da lugar al uso de un registro informal, cargado de expresiones populares, frases exclamativas, verbos que reenvían a la oralidad, entre otros elementos:

11. Pero, ¿entonces hay que dejar que los mocosos hagan siempre lo que les dé la gana? (Giberti, 1968, t.II, p. 236)

12. Quiere ése y nada más que ése y no hay tu tía. (sic) (Giberti, 1968, t.II, p. 182)

13. ¡Por fin!..., decimos, alguien que enfoca sensatamente el problema (Giberti, 1968, t.II, p.177)

14. El "insuficiente" suele provocar verdaderos dramas familiares y hora es que desde aquí hablemos un poquito de esta palabra fastidiosa. (Giberti, 1968, t.III, p. 64)

En estos fragmentos detectamos que el lenguaje al que se recurre se distingue del lenguaje característico de un enunciador experto y objetivo. Se observan palabras coloquiales como "mocosos", frases coloquiales como "no hay tu tía" (sic), verbos que remiten al código oral como "hablar" y el uso de exclamativas por las que se cuela la afectividad.

En sintonía con este registro, aquello que se presenta como complejo, difícil al entendimiento del otro, se lo suprime:

15. Un psicólogo de la infancia, de nombre muy complicado, ha dado esta hermosa definición: "El niño es una sustancia que juega". (Giberti, 1968, t.II, p. 162-163)

En este ejemplo, observamos que se opta por omitir el nombre del psicólogo debido a su complejidad. El acento está puesto así en la definición que se elabora sobre el niño y no en quién la ha formulado. 
El tono conversacional, en segundo término, se revela a partir del diálogo permanente que se establece con el lector. Antes de abordar esta característica, es importante ubicar el destinatario al que se dirigen estos volúmenes. En el tercer apartado hemos señalado, siguiendo la letra del prólogo, que las notas están destinadas a toda la familia: madre, padre, abuela, hijos. No obstante, de la lectura de los artículos se desprende que, en verdad, el destinatario privilegiado es la madre:

16. Entonces, usted, señora, que se desayuna cuando todavía es de noche y que almuerza un sándwich sobre el escritorio monótono y opaco (Giberti, 1968, t.I, p. 142)

En esta cita, la incorporación del apelativo visibiliza el lugar que la madre ocupa dentro de estos escritos. La divulgadora/enunciadora se dirige explícitamente al padre únicamente en cuatro momentos:

17. Y usted, señor, acuérdese que ahora está viviendo no como hijo sino como esposo y como padre (Giberti, 1968, t.I, p. 200)

Incluso, las ocho notas que se dirigen a la figura del padre (Giberti, 1968, t. I, p. 173-193) no se lo interpela como su interlocutor directo.

Ahora bien, la voz del lector, del público, aparece a lo largo de todos los textos preguntando, opinando, realizando alguna objeción. De esta manera, se acentúa la proximidad entre la divulgadora/enunciadora y su interlocutor.

18. “¿Pero entonces (estoy oyendo materialmente la pregunta) tengo que dejar que mi hijito se ponga el dedo en la nariz, sabiendo que es una cosa asquerosa?" (Giberti, 1968, t.I, p. 153)

19. "Peor es que hay padres que no son cariñosos"... podrán acotar algunos. (Giberti, 1968, t.I, p. 68)

20. Claro; me dirán que no es tan grave como para dedicarle un escrito; sí que lo es. (Giberti, 1968, t.III, p. 49)

En el ejemplo 18, aparece una cita textual con la pregunta de una hipotética madre/lectora, que sirve como disparadora de un comentario. Es interesante destacar que se utiliza el verbo "oír", verbo que nos reenvía a la oralidad a la que hacíamos referencia en párrafos anteriores. Luego, 
en el fragmento 19 se enuncia una posible opinión del lector. Por otra parte, los comentarios que se vierten podrán ser compartidos o no con la enunciadora. Esto ocurre en el recorte 20.

En algunos casos, asimismo, no se verbaliza el pensamiento del lector, pero, a partir de lo enunciado por la divulgadora/enunciadora, se puede reconstruir aquello que ella supone podrían ser sus comentarios.

21.la verdad es que las tácticas son variadas y la última anécdota que escuché, fue la de la muchacha de servicio que hacía dormir al chiquito obligándole a oler gas. (Sí, el de la cocina.) (Giberti, 1968, t.II, p. 24)

En este ejemplo, la respuesta "Sí, el de la cocina" le atribuye al lector una posible intervención que no aparece aquí explicitada.

Finalmente, es interesante subrayar que no solamente la divulgadora / enunciadora materializa el pensamiento del lector y le responde, sino que también emplea la segunda persona para dirigirse a él:

22. Recuerde que está preparando un ser humano para convivir con otros y que el amor debe ejercitarse desde la niñez en todas sus formas y excelencias (Giberti, 1968, t.I, p. 68)

23. Yo no sé si ustedes habrán estado alguna vez en un hospital para niños, en alguna sala de niños o en algún servicio hospitalario con niños. (Giberti, 1968, t.I, p. 78)

A partir del uso de la segunda persona, el lector se siente interpelado, convocado a participar de la escena enunciativa que se despliega.

\subsection{El lugar del Otro materno}

Hasta aquí hemos afirmado que en Escuela para padres se advierten ciertos rasgos que buscan acortar la distancia entre la voz de la divulgadora/enunciadora y la voz del lector. Entre otros aspectos, hemos sostenido que la divulgadora/enunciadora apela a la imagen de "mujer común", desde la que enuncia los diferentes relatos. Esta imagen tiene, como efecto, facilitar la identificación del público con lo que se narra. Ahora bien, en este punto analizaremos que esta imagen, en verdad, habilita otra que remite no tanto a la proximidad o no con el lector, sino al tipo de vínculo que con él se establece: la imagen del Otro materno. En efecto, una recorrida por los tres volúmenes nos permite 
ubicar que la voz de la divulgadora/enunciadora se construye desde el lugar del Otro materno, un Otro que, en tanto tal, es garante del decir. En esta imagen, en la que la divulgadora/enunciadora representa a $L a$ madre $^{14}$, el otro, el lector, queda desplazado al lugar del hijo ${ }^{15}$. En lo que sigue, desplegaremos algunas características que están asociadas a esta configuración.

En primer lugar, notamos cierta tensión entre la propuesta de lectura y el tono en el que estos textos están escritos. En este sentido, los artículos, por un lado, se ofrecen como un espacio de diálogo y de reflexión. Encontramos, siguiendo esta línea, diversos fragmentos que invitan esta lectura. Veamos dos de ellos:

24. En realidad, dar consejos a la futura mamá me parece algo así como una forma de la beneficencia psicológica o de la ortopedia mental; lo importante es que ella misma reconozca cuál es su actitud frente a su nuevo estado (Giberti, 1968, t.I, p. 132)

25. Los puntos de vista expuestos no son nuevos, pero conviene que se conozcan y discutan en una Escuela Para Padres, ya que las escuelas no están hechas para repetir, sino para dialogar. (Giberti, 1968, t.II, p. 182)

En esta selección hallamos que, por una parte, en 24 se adopta una posición crítica respecto de la posición de consejero, ya que el fin es que el lector pueda reconocer por sí mismo su actitud; y, por la otra, en la cita 25 se contrapone la acción de repetir con la de dialogar. Según la divulgadora/enunciadora, la propuesta está enraizada en el diálogo.

No obstante, en los textos observamos un tono imperativo que no se aviene a lo allí mencionado. En el diálogo que se entabla con el lector, en numerosas oportunidades, la divulgadora/enunciadora no solamente comenta, responde y aclara las intervenciones del interlocutor, sino que también lo reprende:

26. No, señora, no. Mil veces no. Usted está confundiendo derechos con privilegios. (Giberti, 1968, t.II, p. 100)

14 No podemos dejar de reparar aquí la singularidad y la resonancia que el nombre de la escritora -Eva- adquiere tanto en las escrituras bíblicas como en la historia de la Argentina.

15 En este sentido, podría pensarse que el título "Escuela para padres" no solamente reenvía al fin didáctico de la publicación, sino también ubica al padre en el lugar del niño. 
27. ¿Quién le enseñó a mentir? Usted, señora. (Giberti, 1968, t.II, p. 223)

28. “Pero si sos un hombre... no llorés más, si no duele!..”. Mentira, señora, mentira. Absolutamente falso. Duele, y mucho. (Giberti, 1968, t.II, p. 306)

En estos fragmentos, se desprende que la divulgadora/enunciadora cuestiona fuertemente el accionar de la madre y, a su vez, lo desaprueba a partir de un tono que refleja una posición asimétrica. A través del uso de apelativos, la madre se encuentra explícitamente interpelada en estas escenas, en la que queda en un lugar similar al de una niña "regañada" por su propia madre.

En un artículo posterior, Giberti (1996) cuestiona esta escritura, este estilo que describe como "autoritario", porque afirma que, sin proponérselo, reproduce aquello que ella intenta modificar. Podría pensarse, en esta dirección, que la divulgadora/enunciadora convoca a los lectores a participar de una escena que, en definitiva, imita el modelo de familia tradicional, modelo que definió la niñez de aquellos que leen estas notas y que contribuye a promover su identificación. Veamos un ejemplo en el que se recuerda la educación anterior:

29. Hace muchos años, treinta o cuarenta, este señor era un chiquillo alegre, juguetón, normal; pero tenía una mamá que sostenía que:

“- A los chicos no hay que malcriarlos: especialmente con los varones, hay que ser severa (...)"

(... ) "Fulanito, levántate que tenés que ir a la escuela..."

“-Pero hijo, iquedate quieto!" (Giberti, 1968, t.I, p. 63)

Podría señalarse que las directivas de esta madre se replican en las directivas que la voz de la enunciación realiza a sus lectores.

En segundo lugar, en consonancia con este disciplinamiento, la divulgadora/enunciadora caracteriza la maternidad y la paternidad desde las obligaciones que esta acarrea. De lo que se trata, pues, es de cumplir con los deberes que la función materna y la función paterna imponen. 
30. No se trata de como son los padres, sino de cómo deben ser. (Giberti, 1968, t.I, p. 68) (sic)

31. Usted trabajó todo el día. Seis, siete, ocho horas de actividad múltiple, imperativa. Está cansada, nerviosa, harta, fastidiada (...).

(...) usted no tiene derecho a la rabieta, ni al fastidio ni a ninguna forma de estridencia. Le guste o no, no tiene derecho a estar nerviosa por razones de trabajo, frente al hijo que está esperando un sorbo de mamá. (Giberti, 1968, t.I, p. 143-144)

En estos ejemplos se evidencia la importancia que la divulgadora/ enunciadora le asigna a las obligaciones de los padres.

En tercer lugar, la imagen que configura la voz de la divulgadora/ enunciadora y que hemos denominado el Otro materno se presenta como un lugar de todo-saber. Dicho en otras palabras, esta imagen se presenta como un Otro investido de un saber absoluto que no tiene grietas ni fisuras ${ }^{16}$. Por este motivo, en diversas ocasiones los principios que se formulan se enuncian a modo de leyes:

32. La segunda ley es la de la modalidad; mucho más necesario que hacer al niño caricias concretas, específicas y especializadas, los padres deben hacer lo cotidiano y corriente de un modo invariablemente cariñoso. (Giberti, 1968, t.I, p. 66)

33. En tal caso, la regla de oro es no dar absolutamente importancia alguna al desborde del pequeño (Giberti, 1968, t.II, p. 133)

En estas citas, notamos que los términos empleados "ley" y "regla", que reenvían al campo semántico judicial, buscan regular las conductas de los padres.

Por otra parte, estas leyes están en relación con la lógica causalista y determinista que le da forma al saber que se menciona en los textos ${ }^{17}$ y que puede sintetizarse en el enunciado "x causa q". En efecto, de las

Como analizaremos en el apartado siguiente, la duda se presenta eliminada.

17 Esto ya ha sido señalado por Carpintero y Vainer (2004, p. 127). 
notas se desprende que el accionar de los padres determina la aparición de ciertas problemáticas:

34. La ausencia del tratamiento individual y afectuoso convierte a los niños en minorados psíquicos, en enfermos, y cuando sobreviven traducen su desdicha a lo largo de los años a través del delito, el trastorno mental, la inadaptación. (Giberti, 1968, t.1, p. 75)

En este ejemplo, la afirmación, a través del presente del modo indicativo, no da lugar a dudas o a posibles interpretaciones. La consecuencia final es, entonces, la delincuencia o la enfermedad mental.

Esta lógica presenta una doble implicancia y que, por ende, produce un doble efecto de sentido. Por un lado, si "x causa q", eliminar x, entonces, supone eliminar q. Este primer sentido conduce a construir un imaginario en el que las pautas de conducta que se especifican garantizan los resultados perseguidos: criar un niño "seguro", "normal" y "no neurótico". Pero, por el otro, si "x causa q", no despejar x motiva la aparición forzada de q. Esta segunda implicancia es la que despierta el tono fatalista en el que los artículos están escritos:

35. Lo grave reside en que se ha convertido de este modo en un foco pernicioso, peligro para la salud mental del resto de su familia (Giberti, 1968, t.I, p. 37)

36. El dominio no es un camino: es un despeñadero; arriesgar a un niño por él, puede costar su vida psicológica. (Giberti, 1968, t.II, p. 135)

37. Si lo hace, dominará a su hijo, lo convertirá en un incondicional de su grito o de su orden o de su voluntad, pero como persona lo deformará para siempre. (Giberti, 1968, t.II, p. 239)

En estos fragmentos, que están asociados al campo de la salud mental, se advierte el empleo de términos que plantean un panorama trágico y fatal: "grave", "peligro", "costar", "deformar". En el ejemplo 37 se evidencia un adverbio temporal que marca la fijeza de las consecuencias. De esta forma, en este imaginario, la divulgadora/ enunciadora, en tanto Otro materno, a modo de oráculo, predice el futuro de los niños en el caso de no seguir con las indicaciones que se formulan. El daño que se genera es irreversible. 


\section{La construcción del saber}

Luego de analizar el dispositivo enunciativo en Escuela para Padres, nos focalizamos ahora en el modo o los modos en que el saber se construye en estas páginas. Antes de iniciar este estudio, es esencial recuperar el rol sustantivo que la divulgadora/enunciadora le atribuye a este saber. En efecto, de la lectura se evidencia el lugar destacado que ocupa la ciencia:

38. Para la mujer del siglo XX hay una sola forma de acceder a la plenitud de su vida y de su sexo: conocer, saber, enterarse, medir el pulso de su siglo y acomodar a él su personalidad. (..)

Mostrar los caminos que la ciencia y la investigación ofrecen a la mujer para conocerse a sí misma, para aliviar sus tensiones y liberarse de sus miedos y alcanzar una mejor forma de vida, en la que el sexo constituya una fortaleza y no una debilidad, será tarea de educadores con visión de futuro. (Giberti, 1968, t.I, p. 117)

39. (...) es necesario decir mucho más acerca de un problema que está matando chicos que la ciencia se encargó de salvar. (Giberti, 1968, T II, p. 287)

En estas citas, se establece una asociación estrecha entre la vida y la ciencia. En la primera, la divulgadora/enunciadora resalta la relación entre la educación, el aprendizaje, la ciencia y la vida de la mujer. En la segunda, enfatiza el vínculo entre la ciencia y la vida del niño. Al igual que en el prólogo, la ciencia se manifiesta aquí por medio de personificaciones que realzan sus cualidades. Este aspecto está en sintonía con lo que Authier (1982) señala respecto de la sacralización del saber en los textos de divulgación.

En los siguientes sub-apartados, por un lado, nos proponemos rastrear la incorporación de la palabra del experto en estos artículos; por el otro, intentaremos estudiar cómo se presenta el lenguaje psicoanalítico en el discurrir discursivo.

\subsection{La palabra del experto}

Un recorrido por los tres volúmenes nos advierte el lugar significativo que la palabra ajena ocupa en el entramado discursivo. En efecto, la 
divulgadora/ enunciadora cita diversos autores, a los que reiteradamente denomina técnicos o expertos: por un lado, la palabra de psicoanalistas; por el otro, autores pertenecientes a diferentes dominios del saber. No todas las notas incorporan estas voces autorizadas, pero su presencia, en verdad, se reitera en una amplia mayoría. En primer lugar, los psicoanalistas citados visibilizan la posición teórica de la divulgadora/ enunciadora. En efecto, las lecturas que se desprenden de estos textos y los autores de referencia plasman un escenario en el que la escuela kleiniana, aquella a la que la Asociación Psicoanalítica Argentina de aquel entonces adscribe, se encuentra ausente. Las voces de Erich Fromm, Alfred Adler, Carl Jung, Eric Erikson, Karen Horney, Anna Freud, John Bowlby, entre otras, son aquellas que más se escuchan. En segundo lugar, las voces de médicos (Florencio Escardó, Rof Carballo), sociólogos (Gino Germani), antropólogos (Bronislaw Malinowsky, Margaret Mead), filósofos (Sófocles, Cicerón), escritores (Herman Hesse, Dostoievski), psicólogos (Piaget, Watson), músicos (Maurice Ravel), científicos (Einstein), pedagogos (Pestalozzi) - por nombrar unos pocos- recuerdan aquí y, a su vez, traslucen la importancia que ocupan los distintos saberes en la construcción del andamiaje teórico de Freud. Esta relevancia se refleja, incluso, en que se cita con mayor frecuencia estas voces $(72,1 \%)$ que las voces de los propios psicoanalistas $(27,9 \%)^{18}$.

El análisis detenido de la emergencia de la palabra ajena en estos textos nos revela que esta adopta cuatro modalidades diferentes, a saber: cita textual, cita de reformulación, cita mixta y cita mención. ${ }^{19}$

40. Erich Fromm escribió una vez que "somos eficaces pero algo obtusos" y no podemos menos que darle la razón (Giberti, 1968 , t. I, p. 43)

41. Si recordamos que, al decir de Eric Fromm, toda idea parte de una matriz emocional, no resultará difícil comprender cuáles son las experiencias emocionales de aquellos niños que provienen de culturas, de formas de vida prepotentes, limitativas, agresivas, si se los compara con aquellos que han sido formados en disciplinas menos rígidas, más 
comprensivas y menos exigentes (Giberti, 1968, t. II, p. 22)

42. Morris Zelditch (h.) dice que "un sistema debe diferenciar comportamientos y actitudes para seguir existiendo como tal", y que también es una condición para mantener su estabilidad que se produzca una especialización en la responsabilidad acerca de las actitudes y comportamientos implicados. (Giberti, 1968, t.I, p. 98)

43. Los doctores Goldfarb, Burlingham, Ana Freud y Madame Aubry confirmaron los resultados de las investigaciones de Spitz (Giberti, 1968, t.I, p. 73).

Mientras que en el ejemplo 40 se cita textualmente al psicoanalista Erich Fromm, en el fragmento 41 es la reformulación aquella preferida para incorporar su palabra. En la cita 42 aparece la voz del sociólogo a partir de una cita mixta, en la que se combina literalidad y reformulación. Finalmente, en el último ejemplo se mencionan diversos autores. En ninguno de los casos se explicita el origen de las referencias. Incluso, en los primeros dos ejemplos, la indeterminación del tiempo, a través del circunstancial temporal "una vez", y la generalidad que se infiere de la expresión "al decir de", refuerzan esta ausencia.

Una mirada más cercana sobre el empleo de estas modalidades nos indica, por un lado, que la cita textual es la que presenta mayor frecuencia de aparición (35,8\%), seguida por la cita reformulación $(21,1 \%)$, la cita mixta $(8,9 \%)$ y la cita mención $(7,9 \%)^{20}$. Podría pensarse que el valor que adquiere incluir la palabra del otro en su versión original se corresponde con el lugar significativo que ha ocupado el lenguaje en el psicoanálisis desde su nacimiento. Por el otro, nos revela que, acorde al objetivo de las notas, predominan ampliamente las citas en las que no se explicita ninguna referencia $(62,1 \%)$ sobre las que especifican el origen de la fuente $(37,9 \%)$.

Ahora bien, tres aspectos nos resultan claves al momento de analizar el lugar que ocupa la palabra ajena en estos artículos: la ausencia de datos sobre el autor, la claridad de la voz citada y la evaluación positiva de

20 No incluimos en este análisis las citas provenientes de los epígrafes, ya que nos interesa pensar el modo en que la palabra ajena circula al interior de las notas. 
las citas. En primer lugar, en la mayoría de las citas, la divulgadora/ enunciadora no explica quién es el autor al que hace referencia. Esto puede observarse en los ejemplos anteriores -40,41, 42, 43-, en los que no se especifica quién es Fromm, Zelditch, Goldfarb, Burlingham, Ana Freud o Madame Aubry. Esta ausencia permite pensar, o bien que la divulgadora/ enunciadora presupone que el lector conoce a estos autores, o bien que la mención de su procedencia disciplinar no es relevante para el desarrollo discursivo. Solamente se especifica quién es la voz citada en contadas ocasiones.

En segundo lugar, las citas que se incluyen, por lo general, no son ni explicadas ni retomadas con fines aclaratorios. De esta forma, la divulgadora/enunciadora no se presenta como aquella que descifra un saber inaccesible, alejado del lector: construye un espacio familiar, en sintonía con el dispositivo que desplegamos en el punto anterior. Así, este saber se presenta despojado de complejidad y comprensible al entendimiento del lector, por lo que no requiere de "traducción". Los autores, en este entramado, se suman al trabajo discursivo construyendo el saber conjuntamente con la divulgadora/enunciadora:

44. Erich Fromm lo dice claramente: "El padre es quien enseña al niño, el que le muestra el camino hacia el mundo." (Giberti, 1968, t.I, p. 178)

En este ejemplo, la simplicidad con la que se presenta la voz de Fromm se refuerza con el uso del adverbio claramente.

Por su parte, la reformulación de la palabra ajena queda relegada a unos pocos casos. Veamos dos ejemplos en los que se advierten conectores parafrásticos:

45. Es tan profundo ese contacto que se produce entre seres humanos a través de la alimentación que ha llevado a algunos antropólogos modernos a sostener que "la comensalidad puede ser pensada como confirmante, e incluso como constituye del parentesco en un sentido muy real" (W. Robertson Smith). Es decir, que así como existe un parentesco sanguíneo, existe también un parentesco a través del contacto alimentario, de la comida compartida y aceptada. (sic) (Giberti, 1968, t.II, p. 180) 
46. Como ya dijimos que el hombre nace "a medio acabar" necesita encaminar su madurez dentro de un ambiente que lo proteja, un ambiente maternal donde finalice la formación de su corteza cerebral (neocórtex), bajo la advocación de la persona que lo ayuda a crecer: mamá. Es decir, que "el niño acaba la construcción de su sistema nervioso bajo las normas que le dicta con irresistible e inexorable y amorosa tiranía el subconsciente maternal", según escribe el mismo Rof Carballo. (Giberti, 1968, t.II, p. 12-13)

En ambos ejemplos, observamos el empleo del conector parafrástico "es decir". Mientras que en el fragmento 45 se reformula aquello que plantea Robertson Smith, en el 46 se parafrasea el decir de la divulgadora / enunciadora a través de una cita de Rof Carballo. De esta forma, podemos considerar que la voz de la divulgadora/enunciadora presenta una posición simétrica a la de las voces de los autores que se citan.

Finalmente, como último punto, destacamos la aparición de subjetivemas axiológicos en los que se pone de manifiesto la valoración de los trabajos citados. Al igual de lo que plantea Hyland (2010), la duda es aquí eliminada. En ningún momento se pone en discusión el contenido de las citas, ni se vacila respecto de este saber. En contrapartida, se acentúan sus propiedades positivas:

47. Pocos científicos han tratado a fondo el tema, pero entre ellos, las palabras de Eric Fromm se destacan luminosas y aclaradoras. Por eso, para hablar serena y profundamente de este aspecto de la formación del hombre, prefiero transcribir algunos párrafos que él insertara en su extraordinario libro "El arte de amar" (Giberti, 1968, t. I, p. 44)

En el ejemplo 53, se transcribe un fragmento de un libro de Fromm. En este caso, encontramos diversos subjetivemas axiológicos en el que se destacan sus cualidades.

\subsection{El lenguaje psicoanalítico}

En este sub-apartado nos proponemos analizar el modo en que circulan los conceptos psicoanalíticos en las notas de Escuela para Padres. Ya hemos señalado en el segundo apartado que en los textos de 
divulgación el lenguaje científico se suele presentar como un lenguaje distinto al lenguaje del lector. En otras palabras, siguiendo a Authier (1982), estos lenguajes son representados como lenguajes que acarrean una diferencia irreductible. ¿Qué ocurre, entonces, en estos textos?

Un estudio de la aparición de las nociones psicoanalíticas nos permite señalar que el lenguaje psicoanalítico, a diferencia de lo que ocurre con lo que desarrollamos sobre el discurso de la divulgación, se manifiesta aquí como un lenguaje pasible de ser aprehendido por el lenguaje cotidiano. La claridad a la que se apela en la inclusión de la palabra del experto se visibiliza también en el uso de términos psicoanalíticos que se incorporan en los artículos, eliminando rastros de ajenidad y/o complejidad:

48. Lo que sucede es que el marido es un hombre afectivamente maduro y ella no: sigue prendida al ideal paterno. (Giberti, 1968 , t.I, p. 170)

49. (...) para empeorar su situación es frecuente que esa especie de deseo de venganza con que él quiere castigar a sus padres, muriéndose, se convierta en un sentimiento de culpa inconsciente. (Giberti, 1968, t.I, p. 69)

50. Me siento más inclinada a pensar en la identificación con su padre, quien sí era audaz y valiente y cuidó, a través de su ejemplo, fomentar un auténtico prestigio de hombre de honor y de valor. (Giberti, 1968, t.I, p. 178)

En los ejemplos seleccionados, advertimos que la divulgadora/ enunciadora emplea conceptos psicoanalíticos-ideal paterno, sentimiento de culpa inconsciente, identificación-, pero que no los explica. Las nociones psicoanalíticas ingresan, de esta manera, a la lengua cotidiana sin ser problematizadas. Recordemos, en este punto, que en esta época el psicoanálisis recién comienza a instalarse como un saber legítimo y reconocido en la sociedad, por lo que podemos conjeturar que el lector no está aún familiarizado con estos términos. Sin embargo, desde estos fragmentos se podría pensar que la divulgadora / enunciadora le atribuye al público ciertos conocimientos previos.

Asimismo, siguiendo esta misma línea, en algunos de los artículos la divulgadora/enunciadora elabora un diagnóstico de algunos de los casos relatados: 
51. Estamos, una vez más, frente a un caso de neurosis de angustia de origen infantil. Un ser humano desdichado, malogrado debido a la falta de previsión familiar y a la tiranía materna. (Giberti, 1968, t.I, p. 171-172)

Al igual que en los ejemplos anteriores, no se aclara ni se explica cuál es este diagnóstico. Solo se hace referencia a sus graves consecuencias.

En otros tramos discursivos nos encontramos con lo que Authier (1993, 1995) denomina comentarios metaenunciativos. En estos comentarios advertimos que también se produce un pasaje de un lenguaje a otro desde una posición simétrica.

52. Puede prohibirle lo que a él le prohibieron siendo chico y de lo cual no ha podido aún desasirse (solemos llamarlo proyección). (Giberti, 1968, t.I, p. 27)

53. En lenguaje psicoanalítico se conocen estos episodios con el nombre de regresión, y son mucho más frecuentes de lo que puede suponerse, aun entre los adultos y en la vida diaria. (Giberti, 1968, t.I, p. 220)

54. El chico, dócil y manejado con cuidadoso afecto, fue aceptando poco a poco las imposiciones culturales del medio y las exigencias firmes de la familia; fue convirtiendo en propia conciencia las recomendaciones y normas que sus padres le transmitían, internalizando los preceptos éticos, conformando lo que en lenguaje psicoanalítico se llama superego o superyó, hasta que las enseñanzas familiares se transformaron en parte de su pensamiento, nacían de él. (Giberti, 1968, t.III, p. 71)

En estos tres ejemplos se plantea una equivalencia metalingüística entre el término psicoanalítico empleado y la lengua cotidiana con el que se ejemplifica ese término. Podría pensarse, entonces, que se establece una posición igualitaria entre ambos lenguajes, que produce como efecto de sentido una mayor cercanía con el lector. En la cita 52, el nombre técnico aparece señalado, incluso, entre paréntesis. Esto nos permite señalar que para la divulgadora/enunciadora no es un dato relevante que el lector deba conocer. A su vez, observamos que es la propia divulgadora/ enunciadora quien plantea la existencia de un "lenguaje psicoanalítico", que, por otra parte, no se presenta como un lenguaje inaccesible. 
Es importante destacar que solamente en una nota se despliega con mayor profundidad parte de la teoría psicoanalítica y se explica con un poco de detalle algunas concepciones teóricas. Esta nota, titulada "Un laboratorio", parte de la siguiente premisa:

55. "La familia es algo así como un laboratorio de ensayo para la vida futura del niño." (Giberti, 1968, t.I, p. 99)

Al comienzo de este artículo, la divulgadora/enunciadora afirma que desde la familia se pueden formar hombres "para la sana convivencia común" (Giberti, 1968, t.I, p. 99). Para desarrollar esta idea, introduce, a partir de un breve relato, las concepciones de Freud, Adler, Jung, hasta llegar a la escuela de los denominados "nuevos psicoanalistas":

56. Hasta hace poco tiempo se suponía que lo más importante era construir personas individualmente satisfechas $\mathrm{y}$ normales (...).

(...) para ello se revisaron y aplicaron en principio los planteos de Freud, basados en su teoría sexual de la neurosis. A partir de la ciega aceptación de esta escuela, los chicos se convierten en seres complicadamente sexualizados, que esconden sus represiones en el inconsciente para darles salida durante la madurez, en forma de neurosis.

Pero un discípulo rebelde del maestro -(...)- creó una teoría antagónica; se llamaba Alfred Adler y sostenía que aquello que impulsaba al individuo desde pequeño no era sexual, sino el afán de dominio. (...)

A esta altura de la historia entra en el escenario del desenvolvimiento de la psicología un nuevo personaje: Jung. El doctor Jung va a incorporar un nuevo elemento por encima de los impulsos sexuales de Freud y la voluntad de poder de Adler: el alma. (...)

(...) hasta que, en estos últimos diez años, un grupo de estudiosos advierte que hay algo más que las experiencias infantiles como determinantes del trastorno mental: la relación entre el individuo y la sociedad-familia. (Giberti, 1968, t.I, p. 100-101) 
En esta extensa cita vemos que, para explicar las distintas posiciones teóricas respecto del niño, se opta por introducir un breve relato en el que se narra, a modo de cuento, la manera en que los distintos personajes de esta historia lo fueron concibiendo. Como ya hemos sostenido, en este fragmento no se emplea ni la reformulación ni se definen los conceptos empleados. De esta manera, se efectúa una simplificación de la teoría.

A pesar de la proximidad que se establece entre el lenguaje psicoanalítico y el lenguaje del lector, nos encontramos con algunos lugares en los que se establece cierta distancia. Veamos estos raros ejemplos:

57. Todo esto sin mencionar el trasfondo subconsciente de la mayoría de los padres, que quieren realizar en sus hijos aquello que pudieron ser. Lo que técnicamente se llamaría proyectar en los hijos las propias frustraciones. (Giberti, 1968, t.II, p. 171)

58. La escuela psicoanalítica advirtió acerca de las vinculaciones sexuales que existen en estas situaciones que se dan invariablemente en todo niño. Apareció de esta manera el famoso complejo de Edipo, cuyo manejo y planteo es lo suficientemente delicado y respetable como para intentar su comentario en un breve párrafo. En chico, frente a esta rivalidad, no pudiendo hacer frente a su papá, cosa que además no le está permitida y sí le es sancionada, encuentra la salida liberadora en sus juegos. En ellos, se identifica ${ }^{21}$ con su padre, primero lo imita y luego se siente él mismo como si fuera su padre, en sus juegos y en sus conversaciones. (continua) (Giberti, 1968, t.I, p. 184)

59. Por eso el famoso "complejo de Edipo", que con tanto cuidado debe manejarse y al cual conviene referirse con prudencia, muestra aquí uno de sus innumerables matices trasladado a la época adulta del hombre. Incapaz de sobrevivir afectivamente sin una madre protectora, el hombre busca su continuidad en su matrimonio; es el 
inmaduro permanente, perdido sin una mujer que lo oriente." (Giberti, 1968, t.I, p. 151-152)

En estos ejemplos, advertimos diferentes casos en los que la equivalencia metalingüística a la que hemos hecho referencia aparece subvertida. En el ejemplo 63, el uso del condicional no permite crear una simetría entre el lenguaje del lector y el lenguaje psicoanalítico. En el fragmento 58, a su vez, el empleo de la itálica destaca el término y lo diferencia de su referencia habitual. Finalmente, es interesante destacar la alusión al complejo de Edipo. En las citas 58 y 59, la divulgadora/ enunciadora realiza un comentario sobre el tratamiento de este complejo. Afirma que es necesario manejarlo con prudencia y delicadeza. No obstante, no explica en qué consiste este complejo -el uso del adjetivo famoso conllevaría cierta familiaridad con el lector-. Consideramos aquí que la no aclaración de este concepto no está en relación con la distancia que se establece entre el lenguaje psicoanalítico y el lenguaje del lector, ni en su dificultad. Por el contrario, pensamos que esta omisión reenvía al tabú asociado a la existencia de una sexualidad infantil. Incluso, en el segundo tomo, la divulgadora/enunciadora recuerda el mito de Edipo, pero solo refiere al desciframiento del enigma (Giberti, 1968, t.II, p. 44). No recupera el asesinato del padre de Edipo a manos de su hijo y el posterior casamiento con su madre.

\section{Conclusión}

En 1957, el psicoanálisis comienza gradualmente a adquirir una mayor visibilidad en la comunidad y a instalarse lentamente en los diferentes ámbitos sociales. Este estudio nos ha permitido analizar diversos aspectos de Escuela para Padres de Eva Giberti, una publicación que en esos años inaugura el discurso de la divulgación del psicoanálisis y alcanza una fuerte popularidad al acompañar a los padres en la crianza de sus hijos desde una mirada más próxima a este nuevo saber.

En primer lugar, el trabajo ha revelado que en estos textos la divulgadora/enunciadora no se presenta como una simple mediadora entre el público lector y el saber del experto, sino que, por el contrario, las imágenes que se construyen en torno a su figura y al vínculo con el enunciatario presentan distintos matices y generan diversos efectos de sentido en el entramado discursivo. En este momento, en el que las ideas psicoanalíticas empiezan a formar parte del discurso social, promover 
la cercanía con el otro, a través de la acentuación de la comunidad con el lector y la apelación al tono conversacional, permite que este otro se identifique con los temas que se abordan a través de un saber que es aún incipiente, contribuyendo, de esta manera, al fin explicativo de las notas. Por otra parte, la posición desde la que enuncia la divulgadora/ enunciadora y que hemos denominado el lugar del Otro materno recupera el modelo de familia tradicional, con el que el lector está familiarizado y en el que se puede reconocer.

En segundo lugar, y en sintonía con el dispositivo enunciativo encontrado, se ha advertido que el nuevo saber al que se apela no se manifiesta como inalcanzable, cerrado a la comunidad psicoanalítica, o alejado del entendimiento del lector. Por el contrario, la inclusión de la palabra ajena, que continúa la tradición freudiana a través del predominio de citas textuales y de referencias a otros dominios disciplinares, se manifiesta desde la claridad y la evidencia, familiarizando, de este modo, al público con estas nuevas ideas. Asimismo, la escasa reformulación de términos psicoanalíticos, que son incluidos en las distintas notas para interpretar y explicar diferentes creencias y/o prácticas sociales, permite significar este lenguaje como próximo y accesible al lector. De esta forma, la fluida y natural circulación de estos conceptos no aparece desterrada del lenguaje cotidiano y condenada a deambular únicamente por los pasillos de la institución psicoanalítica. 


\section{Anexo}

\begin{tabular}{|c|c|c|c|c|c|c|c|}
\hline & \multicolumn{2}{|c|}{ Cita Textual } & \multirow{2}{*}{$\begin{array}{l}\text { Cita } \\
\text { Mixta }\end{array}$} & \multirow{2}{*}{$\begin{array}{l}\text { Cita } \\
\text { Reformu- } \\
\text { lación }\end{array}$} & \multirow{2}{*}{$\begin{array}{c}\text { Cita } \\
\text { Mención }\end{array}$} & \multirow[t]{2}{*}{ Total } & \multirow[t]{2}{*}{$\%$} \\
\hline & $\begin{array}{c}\text { Cuerpo } \\
\text { de la } \\
\text { nota }\end{array}$ & Epígrafe & & & & & \\
\hline $\begin{array}{c}\text { Con } \\
\text { referencia }\end{array}$ & 9 & 35 & & & & & \\
\hline $\begin{array}{c}\text { Sin } \\
\text { referencia }\end{array}$ & 59 & 15 & 6 & 26 & 12 & 118 & 62,1 \\
\hline Total & 68 & 50 & 17 & 40 & 15 & & \\
\hline$\%$ & 35,8 & 26,3 & 8,9 & 21,1 & 7,9 & & \\
\hline
\end{tabular}

Tabla 1. Frecuencia de aparición de la palabra ajena en Escuela para Padres.

\begin{tabular}{ccc}
\hline & Autores psicoanalistas & Autores no psicoanalistas \\
\hline 53 & 137 \\
\hline$\%$ & 27,9 & 72,1 \\
\hline
\end{tabular}

Tabla 2. Frecuencia de aparición de aparición de autores psicoanalistas/no psicoanalistas en Escuela para Padres. 


\section{Bibliografía}

Amossy, R. (2005). De la sociocritique à l'argumentation dans le discours. Littérature, 140, 56-71.

Authier, J. (1982). La mise en scène de la communication dans des discours de vulgarisation scientifique. Langue française, 53, 34-47.

Authier-Revuz, J. (1993). Du je de l'intention au jeu du hasard: figures méta-énonciatives du 'Bien Dire'. Cahiers de Praxématique, 20, 87-113.

Authier-Revuz, J. (1995). Les non-cö̈ncidences du dire et leur représentation méta-énonciative. Etude linguistique et discursive de la modalisation autonymique. T. 1 y 2. Paris: Larousse.

Balán, J. (1991). Cuéntame tu vida. Una biografía colectiva del psicoanálisis argentino. Buenos Aires: Planeta Espejo de la Argentina.

Beacco, J.-C. y Moirand, S. (1995). Autour des discours de transmission des connaissances. Langages, 29(117), 32-53.

Beacco, J.-C.; Claudel, C.; Doury, M.; Petit, G.; Reboul-Touré, S. (2002). Science in media and social discourses: new channels of communication, new linguistics forms. Discourse Studies, 4(3), 277-300.

Borinsky, M. (2005). 'Todo reside en saber qué es un niño'. Aportes para una historia de la divulgación de las prácticas de crianza en la Argentina. Anuario de investigaciones. Facultad de Psicología. Universidad de Buenos Aires. Vol. XIII, 117-126.

Calsamiglia, H. (1997). Divulgar. Itinerarios discursivos del saber. Una necesidad, un problema, un hecho. Quark: Ciencia, medicina, comunicación y cultura, 7, 9-18.

Calsamiglia, H. y Van Dijk, T. (2004). Popularization discourse and knowledge about the genome. Discourse and Society, 15(4), 369-389. 
Carpintero, E. y A. Vainer. (2004). Las huellas de la memoria. Psicoanálisis y Salud Mental en la Argentina de los años '60 y '70. Tomo I y II. Buenos Aires: Editorial Topía.

Ciapuscio, G. (2005). Las metáforas en la comunicación de ciencia. En Harvey. A. (Comp.). En torno al discurso. Contribuciones de América Latina (pp. 81-93). Santiago de Chile: Universidad Católica de Chile.

Ciapuscio, G. (2007). Acciones de calificación en conferencias de divulgación científica. Revista internacional de lingüística iberoamericana, 9, 59-76.

Freud, S. (1980). Estudios sobre la histeria. En Obras Completas, tomo II (pp. 151-194). Buenos Aires: Amorrortu.

Fuchs, C. (1994). Paraphrase et énonciation. Paris: Ophrys.

Giberti, E. (1990). Psicoanálisis y divulgación. La experiencia de Escuela para Padres. Todo es Historia, 280, 64-72.

Giberti, E. (1996). Psicoanálisis y medios de comunicación. En Moresco, M. (Comp.). Lunes de Psicoanálisis en la Biblioteca Nacional (pp.135-155). Buenos Aires: Lugar Editorial.

Hyland, K. (2009). Academic Discourse. London: Continuum discourse series.

Hyland, K. (2010). Constructing proximity: Relating to readers in popular and professional science. Journal of English for Academic Purposes, 9, 116-127.

Kabatek, J. (2006). Tradiciones discursivas y cambio lingüístico. En Ciapuscio, G.; Jungbluth, K.; Kaiser, D.; Lopes, C. (Eds.). Sincronía y diacronía de tradiciones discursivas en Latinoamérica (pp.151-172). Madrid: Iberoamericana-Vervuert.

Knudsen, S. (2002). Scientific metaphors going public. Journal of Pragmatics, 35, 1247-1263.

Maingueneau, D. (1987). Nouvelles tendances en analyse $d u$ discours. Paris: Hachette. 
Maingueneau, D. (1999). Ethos, scénographie, incorporation. En Amossy, R. (Dir.), Images de soi dans le discours. La construction de l'ethos (pp.75-100). Paris-Lausanne : Delachaux et Nestlé.

Mapelli, G. (2004). Estrategias lingüístico-discursivas de la divulgación científica. Scrittura e conflitto, Atti del XXII Congresso dell'AISPI, Cd-Rom, vol. II, 169-184. Recuperado de: http:// cvc. cervantes.es/literatura/aispi/pdf/20/ II_12.pdf

Moirand, S. (2003). Communicative and cognitive dimensions of discourse on science in the French mass media. Discourse Studies, 5(2), 175-206.

Moirand, S. (2006). La divulgación de la ciencia y la técnica: ¿Nuevos modelos para nuevos objetos de estudio? Signos, 39(61), 231-358.

Mortureux, (1982). Paraphrase et métalangage dans le dialogue de vulgarisation. Langue française, 53, 48-61.

Orlandi, E. (1987). A linguagem e seu funcionamiento: as formas do discurso. Campinas: Pontes.

Plotkin, M. (2003). Freud en las Pampas. Buenos Aires: Sudamericana.

Savio, K. (abril, 2015). La escritura y la divulgación en psicoanálisis: un recorrido por Escuela para Padres de Eva Giberti. Ponencia presentada en II Congreso de la Delegación Argentina de la ALFAL, La Plata, Buenos Aires.

Savio, K. (En prensa). Aportes de Lacan a una teoría del discurso. Folios, 42, Colombia.

Vezzetti, H. (1996). Aventuras de Freud en el país de los argentinos. De José Ingenieros a Enrique Pichón-Rivière. Buenos Aires: Paidós.

Williams Camus, J. (2009). Metaphors of cancer in scientific popularization articles in the British press. Discourse Studies, 11(4), 465-495. 